\title{
Lesões cervicais granulomatosas não estão associadas a brucelose bovina no sul do estado do Espírito Santo, Brasil
}

\author{
Romeri Pedro dos Santos ${ }^{1}$, Leonardo de Bruyn Denadai ${ }^{1}$, Dyeime Ribeiro Sousa ${ }^{1}$ Dirlei \\ Molinari Donatele ${ }^{*}$, Louisiane Carvalho Nunes ${ }^{1}$, Aparecida de Fátima Madella- \\ Oliveira $^{2}$ \\ ${ }^{\text {I} C e n t r o ~ d e ~ C i e ̂ n c i a s ~ A g r a ́ r i a s ~ d a ~ U n i v e r s i d a d e ~ F e d e r a l ~ d o ~ E s p i ́ r i t o ~ S a n t o ~(C C A U F E S), ~ V i t o ́ r i a, ~ E s p i ́ r i t o ~ S a n t o, ~ B r a s i l ~}$ \\ ${ }^{2}$ Instituto Federal do Espírito Santo (IFES), Vitória, Espírito Santo, Brasil \\ *Autor para correspondência, E-mail: dirleidonatele@hotmail.com
}

RESUMO. Este estudo foi realizado em Anchieta no Sul do Estado do Espírito Santo e teve como objetivo investigar a presença de brucelose nos bovinos abatidos em um matadouro-frigorífico inspecionado pelo Serviço de Inspeção Estadual (SIE) e a relação entre as lesões encontradas na membrana mucosa cervical e a doença. Foram examinados, quanto à presença ou não de lesões cervicais e coletadas amostras sanguíneas de 1.081 bovinos abatidos no período de fevereiro a agosto de 2013. Do quantitativo de bovinos abatidos, 38 (3,5\%) animais apresentavam lesões do tipo granulomatosa na membrana mucosa cervical, ligamento cervical e eventualmente na musculatura adjacente, e destes, apenas $2(5,26 \%)$ bovinos apresentaram-se positivos para brucelose no Teste do Antígeno Acidificado Tamponado (AAT). No entanto, dos $1.034(95,6 \%)$ bovinos sem lesão, $9(0,86 \%)$ apresentaram positividade no AAT. Não houve associação significativa $(\mathrm{P}>0,05)$ entre as lesões cervicais encontradas e a positividade para brucelose. Estes dados aclaram a não associação da brucelose bovina com as lesões granulomatosas encontradas junto ao ligamento cervical na inspeção post mortem, o que sugere a presença de outro agente que não a Brucella abortus.

Palavras chave: Brucella abortus, bursite cervical, inspeção.

\section{Granulomatous cervical lesions are not associated with bovine brucellosis in the southern state of Espírito Santo, Brazil}

\begin{abstract}
This study was conducted in Anchieta in the south of the state of Espírito Santo and aimed to investigate the presence of brucellosis in cattle slaughtered in a slaughterhouse inspected by the State Inspection Service (S.I.E) and the association between the lesions found in the cervical mucous membrane and the disease. Were collected 1081 blood samples in the period from February to August 2013, of these, 38 (3.5\%) specimens showed granulomatous lesions in the cervical mucous membrane type, cervical ligament and possibly the adjacent musculature. Of these, only $2(5.26 \%)$ samples were positive for brucellosis in rose Bengal test (AAT), however of the 1034 (95.6\%) samples without injury 9 $(0.86 \%)$ also showed positive in the AAT. To find out whether there was a association between the lesions found and the presence of brucellosis $(\mathrm{P}>0.05)$. These data do not explain the association of brucellosis with granulomatous lesions found along the cervical ligament in post-mortem inspection, which suggests the presence of an agent other than Brucella abortus.
\end{abstract}

Key words: Brucella abortus, cervical bursitis, inspection. 


\section{Introdução}

A brucelose é uma zoonose bacteriana, com evolução crônica, de caráter granulomatoso difuso e infectocontagioso (Paulin \& Ferreira, 2003). Scholz et al. (2010) relatam a existência de dez espécies independentes de Brucella, com afinidade para cada hospedeiro, sendo a Brucella abortus o agente etiológico que acomete principalmente os bovinos e bubalinos no Brasil. A B. abortus apresenta morfologia colonial lisa ou rugosa, referente à composição bioquímica da parede celular e relacionada com sua virulência (BRASIL, 2006).

A brucelose não possui uma característica ou um sinal clínico patognomônico, manifesta-se de maneira distinta de acordo com o hospedeiro. Nos bovídeos podem causar lesões articulares denominadas higromas, aborto, geralmente no terço final da gestação, não ocorrendo em gestações seguintes, devido ao desenvolvimento da imunidade celular. Nos machos o principal sinal clínico é a orquite, uni ou bilateral (BRASIL, 2006).

Desde o ano de 1975, Langenegger et al. (1975) apud Freitas \& Oliveira (2005) relatavam o isolamento de brucelas e a detecção de anticorpos aglutinantes compatíveis com brucelose de bursites cervicais. Embora os relatos desta enfermidade na literatura sejam poucos, as bursites cervicais frequentemente são associadas às infecções causadas pelo gênero Brucella spp. (Freitas \& Oliveira 2005; Almeida et al., 2000).

Azevedo et al., (2009), estudando a epidemiologia da brucelose no Estado do Espírito Santo verificou que a prevalência da doença no Estado, de janeiro de 2002 a janeiro de 2003 foi de $3,53 \%$, uma porcentagem considerada alta, assim como no Rio de Janeiro $(4,1 \%)$ (KleinGunnewiek et al., 2009) e em Minas Gerais de 1,09\% (Gonçalves et al., 2009). A baixa assistência do Médico Veterinário nas propriedades do Estado $(26,1 \%)$, assim como a pequena porcentagem de propriedades que vacinam as fêmeas bovinas de três a oito meses contra a brucelose $(28,3 \%)$ é reportada por Azevedo et al. (2009) como causa da presente situação da enfermidade no Estado.

A transmissão ao ser humano ocorre pela ingestão de leite e derivados contaminados, contato direto na manipulação de carnes, fetos e membranas fetais, sangue e outros tecidos contendo o agente; caracterizando-a em caráter profissional, pois médicos veterinários, vaqueiros, peões, magarefes, agentes de inspeção e laboratoristas estão mais sujeitos à infecção (Rebhum, 2000).

Existem poucos estudos relacionando as bursites, o que torna difícil a padronização de tais lesões. Almeida et al. (2000) em estudo do tipo caso-controle, relatam as características macroscópicas das lesões com a soropositividade para brucelose em bovinos abatidos sob Inspeção Federal. Freitas \& Oliveira (2005), utilizando meios de cultura Ágar cérebro coração (BHA) e Ágar Brucella, suplementados com antibióticos, isolaram cepas de Brucella spp. em exsudatos de bursite cervical de bovídeos abatidos em Belém, no Estado do Pará. Apesar disso, segundo Pardi et al. (2001), a presença desta lesão associada à brucelose em bovinos não está totalmente esclarecida. Viana et al. (2010) analisaram amostras sanguíneas de bovinos abatidos em frigorífico no Estado do Tocantins, em que relatam a positividade no teste do AAT, contudo, os animais não apresentavam sinais sugestivos de brucelose nos exames ante e "post mortem".

Com base nos estudos apresentados, este trabalho objetivou investigar a ocorrência da brucelose em bovinos abatidos em um matadouro-frigorífico sob Inspeção Estadual no município de Anchieta/ES e avaliar a presença de lesões cervicais sugestivas de brucelose, encontradas durante o exame post mortem, e sua associação com a positividade para o AAT.

\section{Material e Métodos}

A realização deste estudo contou com a parceria do Instituto de Defesa Agropecuária e Florestal do Espírito Santo (IDAF) e de um Matadouro Frigorífico localizado em Anchieta/ES. Neste estabelecimento, o abate é exclusivo de bovinos, com média diária de abate de 60 animais oriundos de todo o Estado do Espírito Santo, principalmente sul do Estado do Espírito Santo.

Foram examinados, quanto à presença ou não de lesões cervicais (bursite), e coletadas amostras sanguíneas de 1.081 bovinos, abatidos no período de fevereiro a agosto de 2013. Para o diagnóstico da bursite adotou-se o método de inspeção rotineira realizada pelo Serviço de Inspeção Estadual (SIE), com a incisão caudo-cranial a partir da terceira vértebra torácica, entre os 
ligamentos cervicais. Após a inspeção realizada pelo Auxiliar do SIE, foi considerado animal portador da brucelose bovina aquele que apresentou qualquer alteração morfológica macroscópica na membrana mucosa da cernelha, podendo estender para o ligamento cervical, sendo caracterizada como bursite.

O sangue foi coletado diretamente da veia jugular externa no momento da sangria e armazenado em tubos estéreis, devidamente identificados de acordo com a ordem de matança na linha de abate, e encaminhados refrigerados ao laboratório de Inspeção de Produtos de Origem Animal da Universidade Federal do Espírito Santo, para obtenção do soro e realização do diagnóstico sorológico da brucelose. O diagnóstico da brucelose contou com método do Antígeno Acidificado Tamponado (AAT) (Tecpar®). A técnica adotada obedece à recomendada pelo Ministério da Agricultura Pecuária e Abastecimento (MAPA) (BRASIL, 2006), cuja presença de grumos caracterizava o animal como reagente, e consequentemente positivo para a brucelose segundo o teste do AAT.

Os resultados encontrados foram submetidos à análise estatística por meio do programa OpenEpi (Dean et al., 2016) e P <0.05. A "Razão de Odds" foi obtida para verificar a possível associação entre a positividade para brucelose e a presença de lesão cervical nos bovinos.

\section{Resultados}

Dentre as $1.081(100 \%)$ amostras analisadas, apenas 11 amostras $(1,0 \%)$ se mostraram reagentes para a brucelose, porém apenas duas destas amostras $(0,2 \%)$ expuseram alterações do tipo granulomatosa na região cervical, sugerindo infecção pela Brucella abortus.

Foram encontrados 38 animais com alterações na membrana mucosa, estes apresentaram característica macroscópica de granulomas, de variados tamanhos e formas, compactos e rígidos, de coloração amarelo esbranquiçado sem odor característico.

Ao observar a tabela 1 , nota-se que dos 38 animais que apresentaram lesão cervical, apenas $2(5,26 \%)$ apontaram soropositividade para brucelose, no entanto, dos 1034 animais que não apresentaram lesão cervical, $0,86 \%$ exibiram resultados positivos frente ao AAT.

Com os dados apresentados na tabela 2 obteve-se a Razão de Odds, cujos resultados estatisticamente não apresentaram associação $(\mathrm{P}>0,05)$, entre a presença da lesão cervical com a positividade para brucelose.

Tabela 1. Frequência de positividade para brucelose bovina e presença de lesão cervical de bovinos abatidos em um matadouro-frigorífico no Sul do Estado do Espírito Santo, 2013.

\begin{tabular}{lccccc}
\hline \multirow{2}{*}{ Exame da bursa cervical } & \multicolumn{4}{c}{ Prova sorológica } & \multirow{2}{*}{ Total } \\
\cline { 2 - 5 } & \multicolumn{2}{c}{ Reagente } & \multicolumn{2}{c}{ Não reagente } & \multirow{2}{*}{$\mathrm{N}^{\circ}$} \\
\cline { 2 - 5 } & $\mathrm{N}^{\circ}$ & $\%$ & $\mathrm{~N}^{\circ}$ & $\%$ & \\
\hline Com lesão & 2 & 5,26 & 36 & 94,7438 & \multirow{2}{*}{1.043} \\
Sem lesão & 9 & 0,86 & 1.034 & 99,14 & 1.081 \\
Total & 11 & 1,02 & 1.070 & 98,98 & \\
\hline
\end{tabular}

Quanto à característica das lesões verificou-se um padrão das mesmas, todas as lesões encontradas apresentaram aspecto granulomatoso de formato irregular e de variados tamanhos, estando presentes na bursa cervical, no ligamento cervical e eventualmente, na musculatura adjacente.

\section{Discussão}

Ao analisar os dados da tabela 2, fica evidente que não existe relação entre a presença de lesões cervicais do tipo granulomatosas (nódulos) e a brucelose. De acordo com o Teste Exato de Fisher, não apresentou diferença significativa ( $P$ $=0,1084)$, evidenciando a não associação entre as lesões cervicais e a positividade sorológica para brucelose nos bovinos.

Estes resultados apresentam concordância com Almeida et al. (2000), que relatam as características macroscópicas das bursites cervicais encontradas em estudo tipo casocontrole realizado em Uberlândia-MG. Destacam 
que os animais sorologicamente positivos para brucelose apresentaram como características do conteúdo das bursites cervicais a presença de fibrina e a presença de projeções digitiformes, e os animais com sorologia negativa para brucelose apresentaram lesões purulentas ou com presença de nódulos. No presente estudo, $100 \%$ das lesões encontradas foram granulomatosas (nódulos).

Tabela 2. "Razão de Odds" referente à positividade para brucelose e a presença de lesão cervical em bovinos abatidos em um matadouro frigorífico no Sul do Estado do Espírito Santo, 2013.

\begin{tabular}{|c|c|c|c|c|}
\hline \multirow{2}{*}{$\begin{array}{l}\text { Exame macroscópico } \\
\text { cervical }\end{array}$} & \multicolumn{2}{|c|}{ Resultado sorológico } & \multirow{2}{*}{ "Razão de Odds" (I.C. 95\%) } & \multirow{2}{*}{$\mathrm{P}$} \\
\hline & Reagente & Não reagente & & \\
\hline Com lesão & 2 & 36 & $6,383(1,383-30,61)$ & $0,1084 *$ \\
\hline Sem lesão & 9 & 1034 & & \\
\hline Total de animais & 11 & 1070 & & \\
\hline
\end{tabular}

I.C. = Intervalo de Confiança.

*Exato de Fisher

Neste estudo, a frequência de $5,3 \%$ dos bovinos que apresentaram lesão, diagnosticados positivamente para brucelose, pode-se atribuir a ocorrência de casualidade e não da associação da doença com a lesão, como comprovado estatisticamente. Pardi et al. (1956) apud Almeida et al. (2000) corroboram os resultados encontrados, quando associam tais lesões com a presença de "nódulos parasitários necrosados e outros calcificados", sugerindo tratar-se de bursites associadas a outras causas que não brucelose. O mesmo não ocorreu com Freitas \& Oliveira (2005), ao analisarem o conteúdo de 52 casos de bursites cervicais de bovídeos abatidos em Belém, no Estado do Pará, constataram 100\% de positividade para sorologia de brucelose, no entanto, o conteúdo das bursites cervicais era do tipo exsudato e não granulomas.

Os dados referentes à ocorrência total da brucelose bovina com as lesões supostamente indicadas como sugestivas da doença, encontrados no presente estudo, revelaram que $0,2 \%(2 / 1081)$ das amostras avaliadas apresentam lesões granulomatosas na região cervical e foram positivas para brucelose. Embora possa ser estatisticamente insignificante, mas presente, contrariam Viana et al. (2010) ao analisarem, por meio do AAT, 845 amostras sorológicas de bovinos abatidos no Estado do Tocantins, destes, 142 reagiram positivamente para brucelose, contudo, dentre os animais abatidos, não se verificou a presença de lesões sugestiva para doença.

Essas pesquisas reforçam a necessidade de estudos mais detalhado para o diagnóstico da brucelose bovina, uma vez que animais com bursites são descartados como suspeitos de serem portadores da Brucella abortus, no entanto estando livres da infecção. Outras vezes, animais clinicamente saudáveis saem para o mercado consumidor, porem sendo portadores da enfermidade, o que gera um risco eminente para a saúde pública.

\section{Conclusão}

Os resultados levam a concluir que as lesões cervicais granulomatosas não estão relacionadas com a brucelose bovina, evidenciando a necessidade de pesquisas para o diagnóstico das causas dessas lesões em bovinos. A brucelose bovina ainda encontra-se disseminado no rebanho bovino da região Sul do Espírito Santo.

\section{Referências bibliográficas}

Almeida, L.P., Reis, D.O. \& Germano, P.M.L. (2000). Brucelose em bovinos com bursite cervical diagnosticada em abatedouro sob inspeção federal. Ciência Rural, 30, 287-291.

Azevedo, S. S., Ferreira Neto, J. S., Dias, R. A., Ferreira, F., Amaku, M., Figueiredo, V. C. F., Lôbo, J. R., Gonçalves, V. S. P., Souza, A. C. \& Vasconcellos, S. A. (2009). Situação epidemiológica da brucelose bovina no Estado do Espírito Santo. Arquivo Brasileiro de Medicina Veterinária e Zootecnia, 61, 19-26.

BRASIL. Ministério da Agricultura, Pecuária e Abastecimento. Manual Técnico do Programa Nacional de Controle e Erradicação da Brucelose e da Tuberculose Bovina (PNCEBT). (2006). Disponível em: $\langle$ http://www.agricultura.gov.br $>$, acessado em 06/06/2016. 
Dean, A.G., Sullivan, K. M. \& Soe, M. M. OpenEpi: Open Source Epidemiologic Statistics for Public Health. Versão. www.OpenEpi.com, atualizado 04/06/2013, Disponível em: $<$ http://www.openepi.com/Menu/OE_Menu.ht m> acessado em 06/06/2016

Freitas, J.A. \& Oliveira, J.P. (2005). Pesquisa de Infecção Brucélica em Bovídeos Abatidos Portadores de Bursite. Arquivos do Instituto Biológico, 72, 427-433.

Gonçalves, V. S. P., DelphinoI, M. K. V. C., Dias, R. A., Ferreira, F., Amaku, M., Ferreira Neto, J. S., Porto, T. B., Alves, C. M., Figueiredo, V. C. F. \& Lôbo, V. J. R. (2009) Situação epidemiológica da brucelose bovina no Estado de Minas Gerais. Arquivo Brasileiro de Medicina Veterinária e Zootecnia, 61, supl. 35-45.

Klein-Gunnewiek, M. F. C., Amaku, M., Dias, R. A., Ferreira, F., Gitti, C. B., Pereira, L. A., Figeiredo, L. A., Lobo, J. R., Gonçalves, V. S. P., Ferreira, J. S. \& Ferreira Neto (2009). Situação epidemiológica da brucelose bovina no Estado do Rio de Janeiro. Arquivo Brasileiro de Medicina Veterinária $e$ Zootecnia, 61, 77-84.

Pardi, M.C., Santos, I.F., Souza, E.R. \& Pardi, H.S. (2001). Ciência, higiene e tecnologia da carne. 2. ed, UFG: Goiânia.
Paulin, L. M. \& Ferreira Neto, J.S. (2003). A experiência brasileira no combate à brucelose bovina. Jaboticabal: Funep, 154p.

Rebhum, W.C. (Ed.). Doenças de gado leiteiro. São Paulo: Roca, (2000). 140p.

Scholz, H. C., Nöckler, K., Göllner, C., Bahn, P., Vergnaud, G., Tomaso, H., Al Dahouk, S., Kämpfer, P., Cloeckaert, A., Maquart, M., Zygmunt, M. S.,Whatmore, A.M., Pfeffer, M., Huber, B., Busse, H.J. \& De, B. K. (2010). Brucella inopinata sp. nov., isolated from a breast implant infection. International Journal of Systematic and Evolutionary Microbiology, 60, 801-808.

Viana, L., Baptista, F., Teles, J., Ribeiro, A.P.C. \& Pigatto, C.P. (2010). Soropositividade e lesões sugestivas de brucelose em bovinos abatidos no estado de Tocantins, Brasil. Arquivos do Instituto Biológico, 77, 517-520.

\section{Article History:}

Received 30 May 2016

Accepted 6 June 2016

Available online 5 July 2016

License information: This is an open-access article distributed under the terms of the Creative Commons Attribution License, which permits unrestricted use, distribution, and reproduction in any medium, provided the original work is properly cited. 